\title{
Product Replacement Policy in a Production Inventory Model with Replacement Period-, Stock-, and Price-Dependent Demand
}

\author{
Subhajit Das, ${ }^{1}$ Amalesh Kumar Manna, ${ }^{1}$ Emad E. Mahmoud (i), ${ }^{2,3}$ Kholod M. Abualnaja, ${ }^{4}$ \\ Abdel-Haleem Abdel-Aty $\mathbb{D}^{\mathrm{D}},{ }^{5,6}$ and Ali Akbar Shaikh ${ }^{1}$ \\ ${ }^{1}$ Department of Mathematics, The University of Burdwan, Burdwan-713104, India \\ ${ }^{2}$ Department of Mathematics and Statistics, College of Science, Taif University, P.O. Box 11099, Taif 21944, Saudi Arabia \\ ${ }^{3}$ Department of Mathematics, Faculty of Science, Sohag University, Sohag 82524, Egypt \\ ${ }^{4}$ Department of Mathematics, Faculty of Applied Science, Umm Al-Qura University, P.O. Box 14949, Makkah, Saudi Arabia \\ ${ }^{5}$ Department of Physics, College of Sciences, University of Bisha, P.O. Box 344, Bisha 61922, Saudi Arabia \\ ${ }^{6}$ Physics Department, Faculty of Science, Al-Azhar University, Assiut 71524, Egypt
}

Correspondence should be addressed to Abdel-Haleem Abdel-Aty; amabdelaty@ub.edu.sa

Received 11 October 2020; Revised 10 November 2020; Accepted 10 December 2020; Published 29 December 2020

Academic Editor: Hijaz Ahmad

Copyright (C) 2020 Subhajit Das et al. This is an open access article distributed under the Creative Commons Attribution License, which permits unrestricted use, distribution, and reproduction in any medium, provided the original work is properly cited.

In the competitive market situation, several companies confer various types of incentives and facilities during product sell to their customers with certain terms and conditions. For the products such as mobile, TV, water purifiers, marshal products, and many more, its corresponding companies offer replacement facility during the guarantee period to enhance the customers' demand. In this study, we have formulated a production inventory model with considering product's replacement facility of the failure product within guarantee periods to their customers. This work also leads two vital assumptions: (i) customers' demand is depending on the replacement period, stock level, and selling price of the product and (ii) the rate of replacement loss of manufacturer's capital is dependent on the replacement period, and it is a nonlinear function. Since the corresponding optimization problem is highly nonlinear, we have solved it by MATHEMATICA software. The concavity of the centre of intervalvalued average profit of the proposed model is shown graphically. In order to justify the validity of the proposed model, a numerical example is considered and solved. Finally, the sensitivity analyses are carried out with respect to the different model parameters.

\section{Introduction}

The first production inventory model was developed by considering the constant demand rate. Later, a lot of production inventory models were established with considering various types of demand rate to overcome the competitive business market. Generally, manufacturing companies of electronics goods such as as TV, fan, refrigerator, mobile phones, and laptops offer warranty policy to their items (if a product is not working during its warranty period, then it can be repaired without cost) to enhance customers' demand. Moreover, some companies provide guarantee period instead to warranty of their produced products in which if a product seems to be not working during its guarantee period, then it can be replaced. This imposes a very crucial implement to attract its customers.

Every business organization maintains some stock of goods in different forms with the purpose of selling them to their targeted customers. Now, the point is then how to manage these stocks so as to minimize the cost and maximize the returns by maintaining an optimal quantity of it. There are many factors to be considered in the management of an inventory, such as (i) reducing the defective rate, (ii) upkeeping of the inventory in such a way that it fulfills the demand of the customer in any given situation, and (iii) implementing different incentives so as to attract customers. The customers' demand is also dependent on the instant stock level. Generally, in a business operation, it is observed 
that stock level imposes a positive impact and selling price imposes a negative impact on customers' demand.

In this work, we have formulated a production inventory model of some electronic goods in which its associated companies provide a guarantee period to its products. Here, we have assumed that the demand of the corresponding products is depending on the three independent arguments: (i) proportionally on the replacement period; (ii) proportionally on stock level; and (iii) negative proportionally on the selling price. Also, the replacement rate is taken as a nonlinear function of the guarantee period. Furthermore, a numerical example is considered and solved to justify the model. Finally, the sensitivity analysis is provided with respect to the different parameters.

This rest of the paper is organized as follows: In Section 2 , the literature review relevant to the model has been discussed. Notation and assumptions are presented in Section 3. Section 4 provides the mathematical formulation of the proposed production inventory model. A numerical example has been given in Section 5. Sensitivity analysis and conclusions with future research have been shown in Sections 6 and 7 .

\section{Literature Review}

We have reviewed some earlier publications by different eminent authors to prepare this model. Several researchers have contributed by their valuable works in the field of production inventory model. Among them, we have reviewed some earlier publications by different eminent authors. The inventory model was first proposed by Harris [1] with considering the constant demand rate and without shortages. Later Resh et al. [2] modified this model by considering a linear increasing demand rate. Taft [3] was the first researcher who established the production inventory model with a constant production rate and demand rate. After that, Lee and Yao [4] modified this EPQ model by adding the concept of imperfect production. Lin [5] integrated a production inventory model with an imperfect production rate by using limitation of raw materials constraint. Succeeding them, Goyal and Cárdenas-Barrón [6] developed an EPQ model with a stochastic defective rate. Sana [7] proposed an EPL (economic production lot size) model with defective production under a stochastic environment. Furthermore, Wee and Widyadana [8] considered partial backlogging in the production inventory model. Bhunia et al. [9] investigated a production inventory model assuming that all the cost components are interval valued. Then, Ghosh et al. [10] reported a production inventory model machine breakdown during production. Jain et al. [11] developed production inventory model with considering repair policy of imperfect items. Also, they considered time-dependent demand and inflation. Manna et al. [12] addressed a two-plant production inventory model for imperfect product under a fuzzy environment. In the same year, Taleizadeh et al. [13] developed an imperfect production inventory model with return and warranty policies. Recently, Rahman et al. [14] developed a production inventory model where the demand and inventory cost parameters are interval valued. Taleizadeh et al. [15] proposed manufacturing and selling tactics under cost sharing and refund agreement in a green supply chain system. Ganesan and Uthayakumar [16] established an EPQ models with learning-dependent demand and production rates under a stochastic environment. They have used a parametric approach and centre-radius optimization technique to optimize the interval-valued average profit. Besides the mentioned research works, a lot of researchers, viz., De et al. [17]; Liao and Sheu [18]; Wee et al. [19]; Taleizadeh et al. [20]; Tsao et al. [21]; Marchi et al. [22]; Manna et al. [23]; Shaikh et al. [24]; Hemapriya and Uthayakumar [25]; and others, made a significant contribution in this area and made this field more perspective for research.

Demand plays a significant role in the inventory system. Several authors suggested various types of demand rate in their inventory model such as price dependent, stock dependent, frequency of the advertisements, time dependent, and warranty period dependent. Kim et al. [26] introduced price-sensitive demand in an EOQ (economic order quantity) model. Burwell et al. [27] proposed a production model of price-sensitive demand. Then, Teng and Chang [28] established an EPQ (economic production quantity) model with considering stock- and price-sensitive demand for perishable items. Valliathal and Uthayakumar [29] considered ramp-type demand in a fuzzy EPQ model for perishable items. Roy et al. [30] provided stochastic demand and rework policy in an EPL (economic production lot size) model. Bhunia et al. [31] proposed price-, time-, and advertisement-dependent demand in a two warehouse inventory models for perishable items. Sadeghi et al. [32] introduced trapezoidal fuzzy demand in a multi-item EPQ model. Manna et al. [33] proposed advertisement-dependent demand in their imperfect production inventory model. Shah and Vaghela [34] addressed advertisement- and timedependent demand in an EPQ model. Also, they analyzed the effect of inflation and rework policy of imperfect items. In the same year, Mallick et al. [35] proposed a stochastic lead time-dependent demand and imperfect production process in a supply chain model. Panda et al. [36] suggested stock- and price-dependent demand in a two warehouse inventory models with partial backlogging. Recently, Manna et al. [23] analyzed the effect of the warranty period- and price-sensitive demand in an EPQ model with defective production. Also, they considered inspection errors and rework policy for imperfect items. Das et al. [37] proposed price-dependent demand and preservation facility for deteriorating items in an inventory model.

\section{Motivation, Notation, and Assumptions}

3.1. Motivation of the Work. In the business world, it is a common scenario that the customers' demand is a most important factor which is dependent on many crucial factors such as price of items, stock level, reliability of products, and many others, and simultaneously, it plays a significant role to push up or push back the market economy. For this regard, every manufacturer wants to catch the customers' attention briefly. That is why different manufacturing companies 
confer various incentives with their respective products to their customers. Several researchers, viz., Teng and Chang [28]; Valliathal and Uthayakumar [29]; Bhunia et al. [31]; Manna et al. [33]; Manna et al. [23]; and others; introduced different types of demand functions in their respective production inventory models. But, for different home appliances such as TV, refrigerator, mobile phones, and other electronics items, their respective companies confer replacement periods against any possible damages of the items, and consequently, it imposes a considerable impact on the demand function of these respective items $[19,38]$. Naturally, there arises a question how to analyse an inventory problem with demand depending on the replacement period (i.e., guarantee period)? Till now, none has formulated an EPQ model in which the customers' demand depending on three factors such as selling price, stock level, and replacement period of the produced items. In this study, a production inventory model with selling price-, stock level-, and replacement period-dependent customers' demand.

3.2. Notation. To formulate the proposed model, the following notations are considered:

$I(t)$ : inventory level at any time $t$

$P$ : production rate of the manufacturer $t_{p}:$ production period (decision variable)

$r_{p}$ : customers' replacement period for a failure product (decision variable)

$s_{p}$ : selling price unit (decision variable)

$T$ : business period

$D\left(r_{p}, I(t), s_{p}\right)$ : customers' demand rate

$\phi\left(r_{p}\right)$ : percentage of replacement quantity

$c_{p}$ : production cost unit

$h_{c}$ : holding cost unit in unit time

A: set-up cost per cycle

$\Pi\left(t_{p}, r_{p}, s_{p}\right):$ zverage profit of the manufacturer

3.3. Assumptions. To formulate the proposed model, the following assumptions are considered:

(i) The production rate of the manufacturer is constant, and the business period of the manufacturer is an infinite time horizon.

(ii) The customers' demand is dependent on the replacement period, inventory level, and selling price of the product. The customers' demand rate is defined by the following form:

$$
\begin{aligned}
D\left(r_{p}, I(t), s_{p}\right) & =\alpha+\beta r_{p}-\gamma s_{p}+\eta I(t), \\
& =d\left(r_{p}, s_{p}\right)+\eta I(t), \quad \text { where } d\left(r_{p}, s_{p}\right)=\alpha+\beta r_{p}-\gamma s_{p},
\end{aligned}
$$

where $\alpha, \beta, \gamma$, and $\eta$ are positive constants.

(iii) Manufacturers offer the replacement facility during a certain time from the delivery time of the product. Due to replacement facility to the customers, there is a replacement loss of the manufacturer's capital. The replacement loss of the manufacturer's capital is dependent on the replacement period $\left(r_{p}\right)$, and the rate of replacement is defined by

$$
\phi\left(r_{p}\right)=\lambda r_{p}^{\delta}, \quad r_{p} \in[0, T],
$$

where $0<\lambda<1$ and $\delta>0$.

(iv) Production period $\left(t_{p}\right)$, replacement period $\left(r_{p}\right)$, and selling price $\left(s_{p}\right)$ of the product are decision variables.

\section{Mathematical Formulation}

A production firm starts the production at the constant rate $P$ and fulfills the customers' demand at the rate $\mathrm{d}\left(r_{p}, s_{p}\right)+\eta I(t)$. The inventory level increases during the production period $\left(0, t_{p}\right]$ due to production rate greater than demand rate, and it is decreased during the period $\left(t_{p}, T\right)$ due to no production but fulfills the customers' demand. The behavior of the inventory level during the period $[0, T]$ is presented in Figure 1.The inventory level $I(t)$ satisfies the following interval differential differential equations

$$
\frac{\mathrm{d} I(t)}{\mathrm{d} t}= \begin{cases}P-\mathrm{d}\left(r_{p}, s_{p}\right)-\eta I(t), & 0 \leq t \leq t_{p}, \\ -\mathrm{d}\left(r_{p}, s_{p}\right)-\eta I(t), & t_{p}<t \leq T,\end{cases}
$$

with the conditions $I(0)=0=I(T)$. The solution of [1] is given by

$$
I\left\{t= \begin{cases}\frac{1}{\eta}\left(1-e^{-\eta t}\right)\left[P-\mathrm{d}\left(r_{p}, s_{p}\right)\right], & 0 \leq t \leq t_{p}, \\ -\frac{1}{\eta}\left[1-e^{\eta(T-t)}\right] \mathrm{d}\left(r_{p}, s_{p}\right), & t_{p}<t \leq T .\end{cases}\right.
$$

Using continuity of $I(t)$ at $t=t_{p}$, we get

$$
T=t_{p}+\frac{1}{\eta} \log \left[1+\frac{P-\mathrm{d}\left(r_{p}, s_{p}\right)}{\mathrm{d}\left(r_{p}, s_{p}\right)}\left\{1-e^{-\eta t_{p}}\right\}\right] .
$$

Now, we have calculated different inventory costs and sales revenue related to proposed production inventory model as follows: 


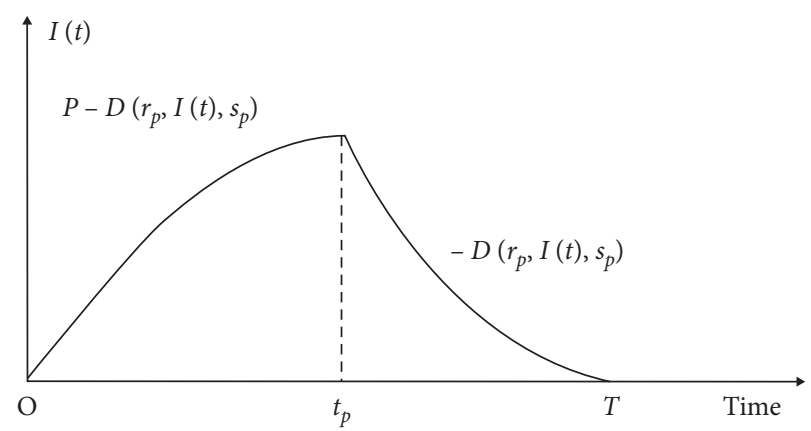

FIGURE 1: Graphical representation of the inventory level of the proposed model.

$\mathrm{PC}($ production cost $)=c_{p} P t_{p}$

$$
\begin{aligned}
\mathrm{HC}(\text { holding cost }) & =h_{c}\left\{\int_{0}^{T} I(t) \mathrm{d} t\right\}, \\
& =\frac{h_{c}}{\eta^{2}}\left[\left\{P-\mathrm{d}\left(r_{p}, s_{p}\right)\right\}\left\{\eta t_{p}+e^{-\eta t_{p}}-1\right\}+\mathrm{d}\left(r_{p}, s_{p}\right)\left\{e^{\eta\left(T-t_{p}\right)}-\eta\left(T-t_{p}\right)-1\right\}\right],
\end{aligned}
$$

$\mathrm{SR}($ sales revenue $)=s_{p}\left\{1-\phi\left(r_{p}\right)\right\} P t_{p}$.

The manufacturer's total profit during $[0, T]$ is given by

$$
\mathrm{TP}\left(t_{p}, r_{p}, s_{p}\right)=s_{p}\left\{1-\phi\left(r_{p}\right)\right\} P t_{p}-c_{p} P t_{p}-\frac{h_{c}}{\eta^{2}}\left[P\left\{\eta t_{p}+e^{-\eta t_{p}}-1\right\}-\mathrm{d}\left(r_{p}, s_{p}\right)\left\{\eta T+\left\{1-e^{\eta T}\right\} e^{-\eta t_{p}}\right\}\right]-A
$$

The manufacturer's average profit is denoted by $\Pi\left(t_{p}, r_{p}, s_{p}\right)$ and defined as follows:

$$
\Pi\left(t_{p}, r_{p}, s_{p}\right)=\frac{\operatorname{TP}\left(t_{p}, r_{p}, s_{p}\right)}{T} .
$$

Now, the goal is to determine optimal values of $t_{p}$ (production period), $r_{p}$ (replacement period), and $s_{p}$ (selling price) which maximize the manufacturer's average profit. Therefore, the optimization problem of the proposed model is defined by

$$
\begin{array}{r}
\text { Maximize } \Pi\left(t_{p}, r_{p}, s_{p}\right), \\
\text { subject to } t_{p}>0, r_{p}>0, s_{p}>0 .
\end{array}
$$

\section{Numerical Illustration}

5.1. Example. A manufacturing company starts the production at the rate $P=1800$ unit/month and continues up to the time $t=t_{p}$ to fulfill the customers' demand during the business period $(T)$. The manufacturer offers replacement facility of the failure product to the customers at a certain time. The fixed demand rate of customers is $\alpha=390$ unit/ month. Also, the replacement period-, selling price-, and stock-sensitive demand parameters are, respectively, $\beta=6.0$ unit, $\gamma=5.0$ unit, and $\eta=0.06$. For offering the replacement policy to the customers, there are two effects such as (i) enhance the customers' demand and (ii) some capital loss for replace the selling product. The parameters related to the replacement policy are $\lambda=0.05$ and $\delta=2$ which are discussed in assumption (iii). The unit production cost of the manufacturer is $c_{p}=\$ 25$. The holding cost and setup cost of the manufacturer are, respectively, $h_{c}=\$ 2 / \mathrm{unit} / \mathrm{month}$ and $A=\$ 500$ per business period. So, the manager of the manufacturing company wants to find the optimal production period $\left(t_{p}=t_{p}^{*}\right)$, optimal replacement period $\left(r_{p}=r_{p}^{*}\right)$ and optimal selling price $\left(s_{p}=s_{p}^{*}\right)$ of the product, and corresponding optimal average profit $\Pi^{*}\left(r_{p}^{*}, t_{p}^{*}, s_{p}^{*}\right)$.

5.2. Solution. The values of model parameters are $P=1800$ unit/month; $\alpha=390 ; \beta=6.0$ unit; $\gamma=5.0$ unit; $\eta=0.06$; $\lambda=0.05 ; \delta=2 ; c_{p}=\$ 25 /$ unit; $h_{c}=\$ 2 /$ unit $/$ month; and $A=$ $\$ 500$ per business period. Applying MATHEMATICA software and the mentioned model parameter values in the average profit function (11) of the proposed model, we get the optimal values of $t_{p}=t_{p}^{*}, r_{p}=r_{p}^{*}$, and $s_{p}=s_{p}^{*}$ which 
gives the maximum average profit $\Pi^{*}\left(r_{p}^{*}, t_{p}^{*}, s_{p}^{*}\right)$. The computational optimal results are given in Table 1 .

Figures 2-4 show that the average profit is concave w.r.t decision variables $r_{p}, t_{p}$, and $s_{p}$.

\section{Sensitivity Analyses}

In this section, we have investigated the effects of the optimum values of $\Pi\left(r_{p}, t_{p}, s_{p}\right)$ (average profit of manufacturer), $t_{p}$ (production period), $r_{p}$ (replacement period of the product), $s_{p}$ (selling price), and $T$ (business period) with respect to four different system parameters $\beta, \lambda, \delta$, and $A$ by changing the values from $-20 \%$ to $+20 \%$. The detail results are shown in Table 2. From Table 2, the following results are observed:

(i) The average profit of the manufacturer is less sensitive directly with respect to replacement-sensitive demand parameter $(\beta)$ and replacement loss of the manufacturer's capital parameter $(\delta)$, whereas it is less sensitive reversely with respect to setup cost (A) and replacement loss of the manufacturer's capital parameter $(\lambda)$.

(ii) Production period of the manufacturer is less sensitive directly with respect to the replacementsensitive demand parameter $(\beta)$ and replacement loss of the manufacturer's capital parameter $(\delta)$, whereas it is less sensitive reversely with respect to replacement loss of the manufacturer's capital parameter $(\lambda)$. On the other hand, it is moderately sensitive directly with respect to setup cost $(A)$.

(iii) Replacement period of the product is equal sensitive directly with respect to replacement-sensitive demand parameter $(\beta)$, and it is equal sensitive reversely with respect to replacement loss of the manufacturer's capital parameter $(\lambda)$. Also, it is large sensitive reversely with respect to replacement loss of the manufacturer's capital parameter $(\delta)$, whereas it is moderately sensitive directly with respect to setup cost $(A)$.

(iv) Selling price of the product is less sensitive directly with respect to the replacement-sensitive demand parameter $(\beta)$, replacement loss of the manufacturer's capital parameter $(\delta)$, and setup cost $(A)$, whereas it is less sensitive reversely with respect to replacement loss of the manufacturer's capital parameter $(\lambda)$.

(v) Business period of the manufacturer is less sensitive directly with respect to the replacement-sensitive demand parameter $(\beta)$ and replacement loss of the manufacturer's capital parameter $(\delta)$. Also, it is insensitive with respect to replacement loss of the
TABLE 1: Optimal results of the proposed model.

\begin{tabular}{lc}
\hline Variables/objective & Optimal value \\
\hline Replacement period $\left(r_{p}^{*}\right)$ in month & 0.2219 \\
Selling price $\left(s_{p}^{*}\right)$ in $\$$ & 53.9354 \\
Production period $\left(t_{p}^{*}\right)$ in month & 0.4081 \\
Business period $\left(T^{*}\right)$ in month & 5.20783 \\
Average profit $\Pi\left(t_{p}^{*}, r_{p}^{*}, s_{p}^{*}\right)$ in $\$$ & 3320.01 \\
\hline
\end{tabular}



FIGURE 2: Concavity representation of $\Pi\left(r_{p}, t_{p}, s_{p}\right)$ w.r.t $r_{p}$ and $t_{p}$.

manufacturer's capital parameter $(\lambda)$. Moreover, it is moderately sensitive directly with respect to setup cost $(A)$.

\section{Practical Implication}

The proposed model can be applied to any manufacturing firm where the manufacturer provides replacement facility during the guarantee period and the customers' demand depend on stock of the produced items. The management of the manufacturing firm offers the product replacement facility to enhance customers' demand and average profit of the company. On the other hand, the customers will be benefited due to the product replacement facility. Here, the customers' demand is dependent on the replacement period, stock, and selling price of the items. Finally, the managers of this type of manufacturing firms will investigate the following characteristics:

(i) What would be the optimal selling price which maximizes the manufacturer's average profit?

(ii) What would be the optimal replacement period which maximizes the manufacturer's average profit?

(iii) What would be the optimal production period which maximizes the manufacturer's average profit? 


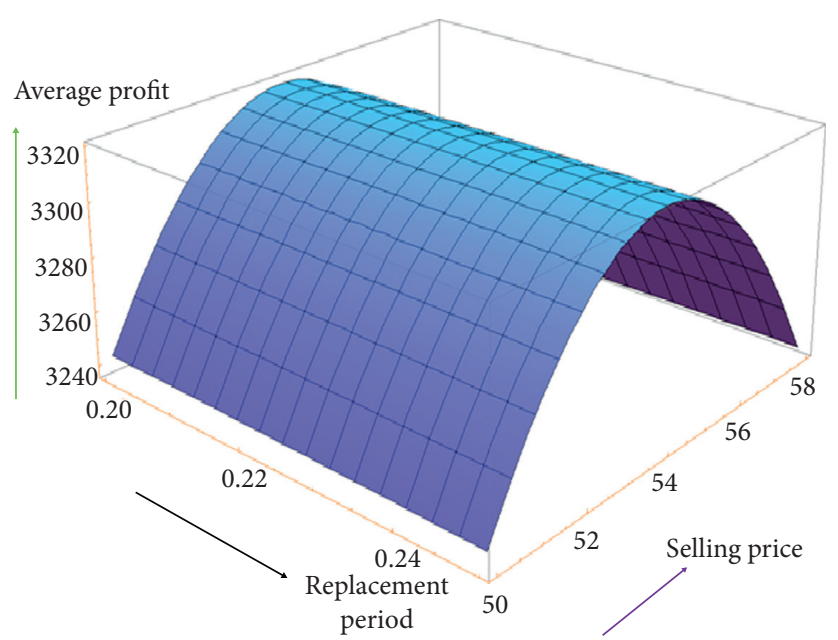

FIGURE 3: Concavity representation of $\Pi\left(r_{p}, t_{p}, s_{p}\right)$ w.r.t $r_{p}$ and $s_{p}$.

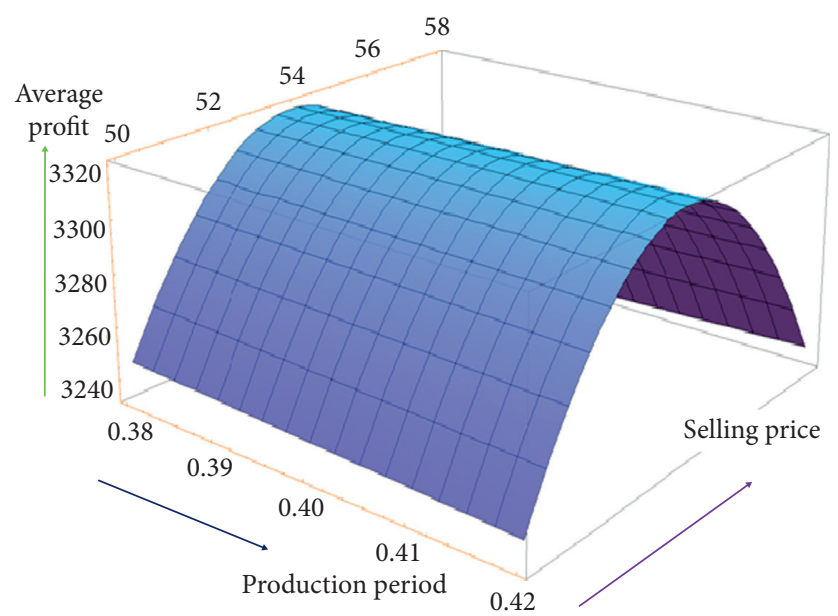

FIGURE 4: Concavity representation of $\Pi\left(r_{p}, t_{p}, s_{p}\right)$ w.r.t $t_{p}$ and $s_{p}$.

TABLe 2: Results of sensitivity analysis with respect to $\beta, \lambda, \delta$, and $A$.

\begin{tabular}{|c|c|c|c|c|c|c|}
\hline \multirow{2}{*}{ Parameters } & \multirow{2}{*}{$\%$ of change of the parameters } & \multicolumn{5}{|c|}{$\%$ change in optimal values } \\
\hline & & $\Pi\left(r_{p}, t_{p}, s_{p}\right)$ & $t_{p}$ & $r_{p}$ & $s_{p}$ & $T$ \\
\hline \multirow{4}{*}{$\beta$} & -20 & -0.20 & -0.25 & -19.84 & -0.12 & -0.10 \\
\hline & -10 & -0.11 & -0.13 & -9.90 & -0.06 & -0.05 \\
\hline & +10 & +0.12 & +0.14 & +9.87 & +0.07 & +0.06 \\
\hline & +20 & +0.25 & +0.30 & +19.70 & +0.14 & +0.12 \\
\hline \multirow{4}{*}{$\lambda$} & -20 & +0.14 & +0.17 & +24.82 & +0.08 & +0.07 \\
\hline & -10 & +0.06 & +0.08 & +11.04 & +0.04 & +0.03 \\
\hline & +10 & -0.05 & -0.06 & -9.04 & -0.03 & -0.02 \\
\hline & +20 & -0.09 & -0.11 & -16.59 & -0.05 & -0.05 \\
\hline \multirow{4}{*}{$\delta$} & -20 & -0.34 & -0.51 & -46.62 & -0.15 & -0.29 \\
\hline & -10 & -0.17 & -0.27 & -21.60 & -0.07 & -0.17 \\
\hline & +10 & +0.17 & +0.29 & +18.63 & +0.06 & +0.18 \\
\hline & +20 & +0.32 & +0.57 & +34.83 & +0.11 & +0.38 \\
\hline \multirow{4}{*}{$A$} & -20 & +0.62 & -13.29 & +0.51 & -0.51 & -12.61 \\
\hline & -10 & +0.30 & -6.59 & +0.25 & -0.25 & -6.23 \\
\hline & +10 & - & - & - & - & - \\
\hline & +20 & - & - & - & - & - \\
\hline
\end{tabular}


To obtain these answers, managers of the manufacturing system may use MATHEMATICA software to solve the corresponding optimization problem (average profit function).

\section{Conclusions and Future Research Direction}

8.1. Conclusions. In this study, a production inventory model is formulated in which the customers' demand is depending on three factors: proportionally on stock level and replacement period and negative proportionally on the price of the items. The proposed customers' demand function is a significant factor to maximize the manufacturer's average profit. Finally, we have investigated the optimal values of selling price, replacement period, and production period of the produced items which are maximizing the manufacturer's average profit. Many manufacturing firms are not convinced about the positive effect on the customers' demand for providing a replacement period on the products. This model helps to the management of the manufacturing firm to attract the customers to purchase more products.

8.2. Future Research Direction. For future investigation, the proposed model can be extended by incorporating the concepts of full/partial backlogging, advanced payment policy, discount facility, and so forth. Also, this model can be discussed in an interval-environment/fuzzy environment or stochastic environment by considering different parameters as imprecise in nature.

\section{Data Availability}

No data were used to support this study.

\section{Conflicts of Interest}

The authors declare that they have no conflicts of interest.

\section{Acknowledgments}

This work was supported by the Taif University Researchers Supporting Project number TURSP-2020/20, Taif University, Taif, Saudi Arabia.

\section{References}

[1] F. W. Harris, "How much stock to keep on hand, factory," The Magazine of Management, vol. 10, no. 2, pp. 135-136, 1913.

[2] M. Resh, M. Friedman, and L. C. Barbosa, "On a general solution of the deterministic lot size problem with timeproportional demand," Operations Research, vol. 24, no. 4, pp. $718-725,1976$.

[3] E. W. Taft, "The most economical production lot," Iron Age, vol. 101, no. 18, pp. 1410-1412, 1918.

[4] H.-M. Lee and J.-S. Yao, "Economic production quantity for fuzzy demand quantity, and fuzzy production quantity," European Journal of Operational Research, vol. 109, no. 1, pp. 203-211, 1998.

[5] C.-S. Lin, "Integrated production-inventory models with imperfect production processes and a limited capacity for raw materials," Mathematical and Computer Modelling, vol. 29, no. 2, pp. 81-89, 1999.

[6] S. K. Goyal and L. E. Cárdenas-Barrón, "Note on: economic production quantity model for items with imperfect quality-a practical approach," International Journal of Production Economics, vol. 1, no. 77, pp. 85-87, 2002.

[7] S. S. Sana, "An economic production lot size model in an imperfect production system," European Journal of Operational Research, vol. 201, no. 1, pp. 158-170, 2010.

[8] H. M. Wee and G. A. Widyadana, "Economic production quantity models for deteriorating items with rework and stochastic preventive maintenance time," International Journal of Production Research, vol. 11, no. 50, pp. 2940-2952, 2012.

[9] A. K. Bhunia, A. A. Shaikh, and L. E. Cárdenas-Barrón, “A partially integrated production-inventory model with interval valued inventory costs, variable demand and flexible reliability," Applied Soft Computing, vol. 55, pp. 491-502, 2017.

[10] P. K. Ghosh, A. K. Manna, and J. K. Dey, "Deteriorating manufacturing system with selling price discount under random machine breakdown," International Journal of Computational Engineering \& Management, vol. 20, no. 5, pp. 8-17, 2017.

[11] S. Jain, S. Tiwari, L. E. Cárdenas-Barrón, A. A. Shaikh, and S. R. Singh, "A fuzzy imperfect production and repair inventory model with time dependent demand, production and repair rates under inflationary conditions," RAIRO - Operations Research, vol. 52, no. 1, pp. 217-239, 2018.

[12] A. K. Manna, J. K. Dey, and S. K. Mondal, "Controlling GHG emission from industrial waste perusal of production inventory model with fuzzy pollution parameters," International Journal of Systems Science: Operations \& Logistics, vol. 6, no. 4, pp. 368-393, 2019.

[13] A. A. Taleizadeh, P. Pourrezaie Khaligh, and I. Moon, "Hybrid NSGA-II for an imperfect production system considering product quality and returns under two warranty policies," Applied Soft Computing, vol. 75, pp. 333-348, 2019.

[14] M. S. Rahman, A. K. Manna, A. A. Shaikh, and A. K. Bhunia, "An application of interval differential equation on a production inventory model with interval-valued demand via center-radius optimization technique and particle swarm optimization," International Journal of Intelligent Systems, vol. 35, no. 8, pp. 1280-1326, 2020.

[15] A. A. Taleizadeh, M. Noori-Daryan, and S. S. Sana, "Manufacturing and selling tactics for a green supply chain under a green cost sharing and a refund agreement," Journal of Modelling in Management, vol. 15, no. 4, pp. 1419-1450, 2020.

[16] S. Ganesan and R. Uthayakumar, "EPQ models with bivariate random imperfect proportions and learning-dependent production and demand rates," Journal of Management Analytics, vol. 37, 2020.

[17] S. K. De, P. K. Kundu, and A. Goswami, "An economic production quantity inventory model involving fuzzy demand rate and fuzzy deterioration rate," Journal of Applied Mathematics and Computing, vol. 12, no. 1-2, p. 251, 2003.

[18] G.-L. Liao and S.-H. Sheu, "Economic production quantity model for randomly failing production process with minimal repair and imperfect maintenance," International Journal of Production Economics, vol. 130, no. 1, pp. 118-124, 2011.

[19] H.-M. Wee, W.-T. Wang, and P.-C. Yang, "A production quantity model for imperfect quality items with shortage and screening constraint," International Journal of Production Research, vol. 51, no. 6, pp. 1869-1884, 2013. 
[20] A. A. Taleizadeh, H. M. Wee, and S. G. J. Naini, "Economic production quantity model with repair failure and limited capacity," Applied Mathematical Modelling, vol. 5, no. 37, pp. 2765-2774, 2013.

[21] Y.-C. Tsao, P.-L. Lee, L.-W. Liao, Q. Zhang, T.-L. Vu, and J. Tsai, "Imperfect economic production quantity models under predictive maintenance and reworking," International Journal of Systems Science: Operations \& Logistics, vol. 7, no. 4, pp. 1-14, 2019.

[22] B. Marchi, S. Zanoni, and M. Y. Jaber, "Economic production quantity model with learning in production, quality, reliability and energy efficiency," Computers \& Industrial Engineering, vol. 129, pp. 502-511, 2019.

[23] A. K. Manna, J. K. Dey, and S. K. Mondal, "Effect of inspection errors on imperfect production inventory model with warranty and price discount dependent demand rate," RAIROOperations Research, vol. 54, no. 4, pp. 1189-1213, 2020.

[24] A. A. Shaikh, L. E. Cárdenas-Barrón, and S. Tiwari, "Economic production quantity (EPQ) inventory model for a deteriorating item with a two-level trade credit policy and allowable shortages," in Optimization and Inventory Management, N. Shah and M. Mittal, Eds., pp. 1-19, Springer, Singapore, 2020.

[25] S. Hemapriya and R. Uthayakumar, "Integrated production inventory model with variable production rate on quality of products involving probabilistic defective under variable setup cost," RAIRO-Operations Research, vol. 54, no. 6, pp. 1723-1756, 2020.

[26] J. Kim, H. Hwang, and S. Shinn, "An optimal credit policy to increase supplier's profits with price-dependent demand functions," Production Planning \& Control, vol. 6, no. 1, pp. 45-50, 1995.

[27] T. H. Burwell, D. S. Dave, K. E. Fitzpatrick, and M. R. Roy, "Economic lot size model for price-dependent demand under quantity and freight discounts," International Journal of Production Economics, vol. 48, no. 2, pp. 141-155, 1997.

[28] J. T. Teng and C. T. Chang, "Economic production quantity models for deteriorating items with price-and stock-dependent demand," Computers \& Operations Research, vol. 2, no. 32, pp. 297-308, 2005.

[29] M. Valliathal and R. Uthayakumar, "Fuzzy economic production quantity model for weibull deteriorating items with ramp type of demand," International Journal of Strategic Decision Sciences, vol. 2, no. 3, pp. 55-90, 2013.

[30] M. D. Roy, S. S. Sana, and K. Chaudhuri, "An economic production lot size model for defective items with stochastic demand, backlogging and rework," IMA Journal of Management Mathematics, vol. 25, no. 2, pp. 159-183, 2014.

[31] A. K. Bhunia, A. A. Shaikh, G. Sharma, and S. Pareek, "A two storage inventory model for deteriorating items with variable demand and partial backlogging," Journal of Industrial and Production Engineering, vol. 32, no. 4, pp. 263-272, 2015.

[32] J. Sadeghi, S. T. A. Niaki, M. R. Malekian, and S. Sadeghi, "Optimising multi-item economic production quantity model with trapezoidal fuzzy demand and backordering: two tuned meta-heuristics," European J. of Industrial Engineering, vol. 10, no. 2, pp. 170-195, 2016.

[33] A. K. Manna, J. K. Dey, and S. K. Mondal, "Imperfect production inventory model with production rate dependent defective rate and advertisement dependent demand," Computers \& Industrial Engineering, vol. 104, pp. 9-22, 2017.

[34] N. H. Shah and C. R. Vaghela, "Imperfect production inventory model for time and effort dependent demand under inflation and maximum reliability," International Journal of
Systems Science: Operations \& Logistics, vol. 5, no. 1, pp. 60-68, 2018.

[35] R. K. Mallick, A. K. Manna, and S. K. Mondal, "A supply chain model for imperfect production system with stochastic lead time demand," Journal of Management Analytics, vol. 5, no. 4, pp. 309-333, 2018.

[36] G. C. Panda, M. A.-A. Khan, and A. A. Shaikh, "A credit policy approach in a two-warehouse inventory model for deteriorating items with price- and stock-dependent demand under partial backlogging," Journal of Industrial Engineering International, vol. 15, no. 1, pp. 147-170, 2019.

[37] S. C. Das, A. M. Zidan, A. K. Manna, A. A. Shaikh, and A. K. Bhunia, "An application of preservation technology in inventory control system with price dependent demand and partial backlogging," Alexandria Engineering Journal, vol. 59, pp. 1359-1369, 2020.

[38] C. Kao and W. K. Hsu, "A single-period inventory model with fuzzy demand," Computers \& Mathematics with Applications, vol. 6-7, no. 43, pp. 841-848, 2002. 